\title{
Peripheral Neuropathy Following Spinal Anaesthesia after DHS Fixation Surgery for Inter-trochanteric Fracture Femur
}

Vikram VK and Yashwant $M$

ACPM Medical College, Dhule, Maharashtra, India

*Corresponding author: Vikram VK, Pediatric Department, Zagazig University, Egypt, Tel: +91-8554917127; E-mail: vikram1065@gmail.com

Received date: December 08, 2015; Accepted date: January 06, 2016; Published date: January 08, 2016

Copyright: (c) 2016 Vikram VK, et al. This is an open-access article distributed under the terms of the Creative Commons Attribution License, which permits unrestricted use, distribution, and reproduction in any medium, provided the original author and source are credited.

\begin{abstract}
Background: Proximal femoral fractures present unique challenges for anaesthetic department involving the peri-operative care of large numbers of older patients with significant co-morbidities. The majority (95\%) of hip fractures occur in patients over the age of $60.75 \%$ occurring in females. More than $98 \%$ of fractures are repaired surgically, for the purposes of analgesia and early rehabilitation. Peripheral neuropathy following spinal anaesthesia is a rare complication following lower limb surgery.
\end{abstract}

Purpose: To ensure proper safety measures while giving spinal anaesthesia to the patients. Multiple attempts and faulty technique may lead to direct trauma to the spinal cord or nerve root.

Material and Methods: 79 yrs old female presented to OPD with complaints of pain over left hip and unable to walk. X-ray showed IT fracture femur. Patient was admitted, investigated and fitness was taken. DHS fixation surgery was performed under spinal anaesthesia. Post-operatively patient developed DVT of the operated leg and neuropathy (loss of movement but intact sensation) of the contra-lateral leg. Low molecular weight Heparin was started for DVT along with elastic stocking to the limb and MRI was done to assess the cause for peripheral neuropathy.

Outcome: Though rare, peripheral neuropathy is a complication of spinal anaesthesia. Damage to nerve roots can occur due to faulty technique or repeated attempts for spinal anaesthesia. Prolonged hypotension following spinal anaesthesia may cause spinal cord ischemia or thrombosis of the anterior spinal artery leading to flaccid paraplegia.

Conclusion: Continuous passive physiotherapy of the lower limbs helps in complete recovery of the neuropathy but at a slow rate.

Keywords: Neuropathy; DVT; Spinal anaesthesia; IT fractureAbbreviations: OPD: Out Patient Department; DVT: Deep Vein Thrombosis

\section{Introduction}

Regional anaesthesia is a preffered anaesthesia in cases of lower limb fractures. Spinal anaesthesia is widely used for cases of Intertrochanteric fracture of femur. Incidence of neurologic complication is reported to be higher with spinal than for epidural anaesthesia [1]. Various causes of neurologic complications have been documented in the literature, as chemical myelitis, injury to the cord, or prexisting neurological lesion [2]. Regional anaesthesia is well known for complications. Major neurological sequelae after central blockade although rare but can be devastating for the patient and the anaesthetist. Postoperative thromboembolism is a potentially lethal complication. Its diagnosis may be difficult, as the classic clinical signs and symptoms are often absent, making a high index of suspicion imperative for diagnosis. We report one such case of Inter-trochanteric fracture femur operated with DHS fixation surgery under spinal anaesthesia, post-operatively developed neuropathy of the contralateral limb and DVT of the ipsilateral limb.

\section{Case Presentation}

79 yrs old female presented to OPD with complaints of pain over left hip and unable to walk. X-ray (Figure 1) showed IT fracture femur. Patient was admitted, investigated and fitness was taken. Surgery was planned and accordingly spinal anaesthesia was given. X-ray LS spine (Figure 2). While giving spinal anaesthesia, 25 gauge spinal needle and lignocaine $2 \%$ was used. Since there was no free flow of cerebrospinal fluid, multiple attempts were taken and patient felt severe pain and electric shock like sensation at the time of insertion of the needle, which she reported immediately. Patient was placed on fracture table and DHS fixation surgery was performed which lasted for 65 mins. Post-operatively patient developed DVT of the operated leg and neuropathy (loss of movement but intact sensation) of the contralateral leg with normal bladder and bowel sensations. Low molecular weight Heparin was started for DVT along with elastic stocking to the limb. 
Citation: Vikram VK, Yashwant M (2016) Peripheral Neuropathy Following Spinal Anaesthesia after DHS Fixation Surgery for Inter-trochanteric Fracture Femur. J Neurol Disord 4: 255. doi:10.4172/2329-6895.1000255

Page 2 of 3

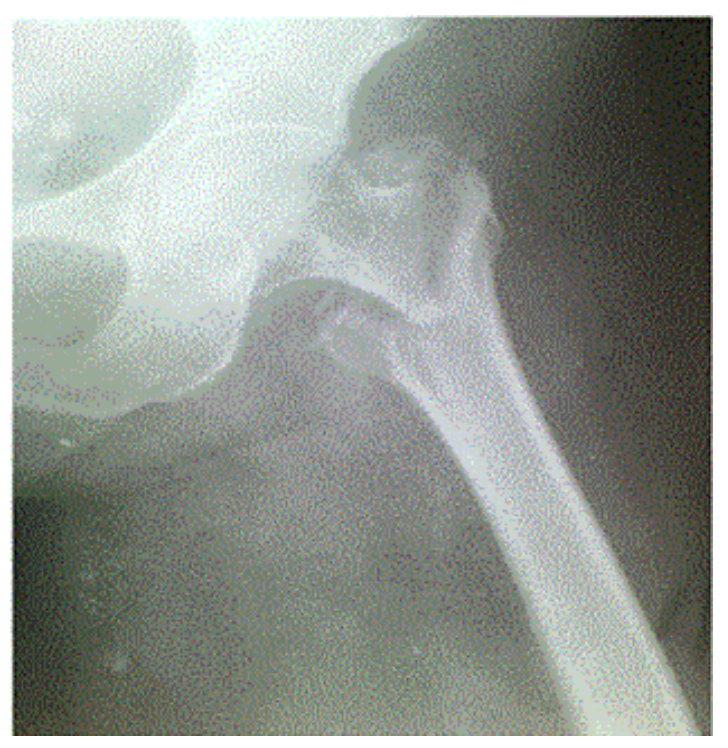

Figure 1: Pre-op X-ray of left hip showing IT fracture.

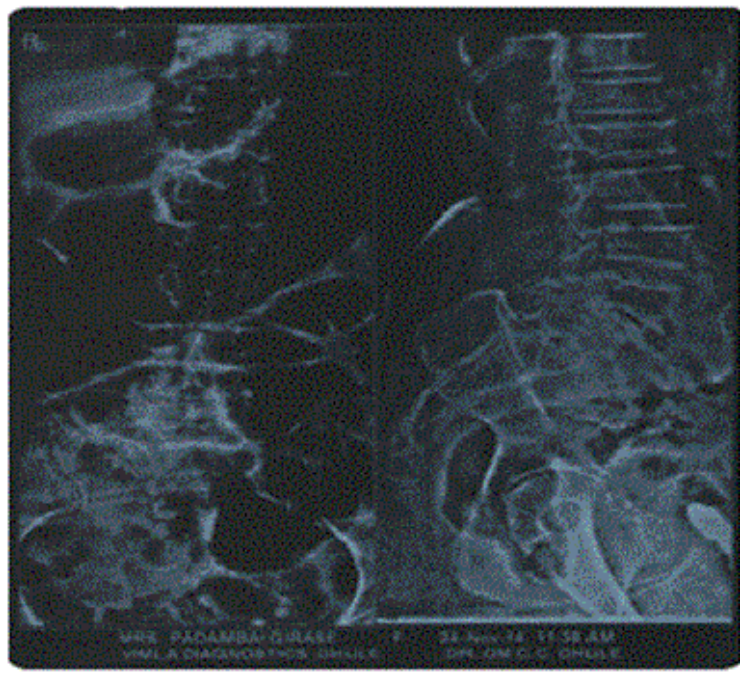

Figure 2: X-ray LS spine.

Doppler was done to assess the vascular status of the limb (Figure 3) and MRI was done to assess the cause for peripheral neuropathy (Figures 4 and 5). Passive physiotherapy was started. But patient died with due course of time and we lost the follow-up.

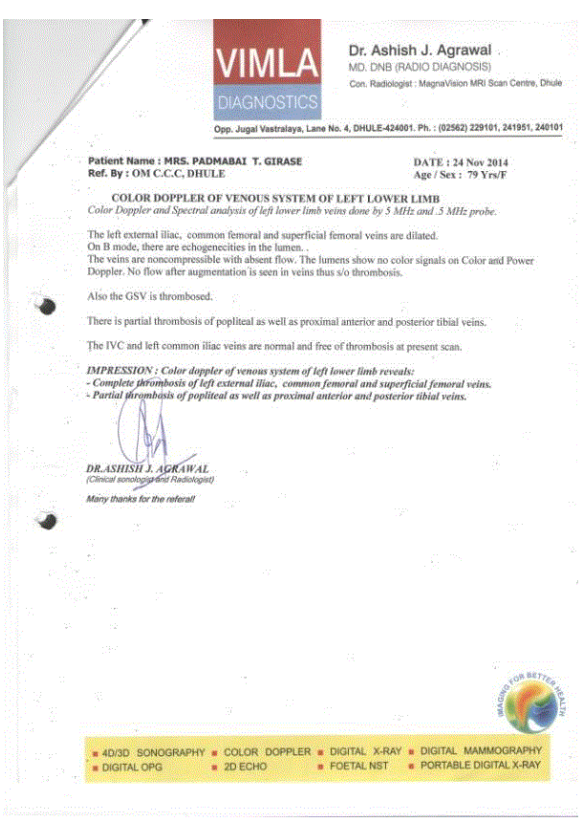

Figure 3: Colour Doppler of the left lower limb.

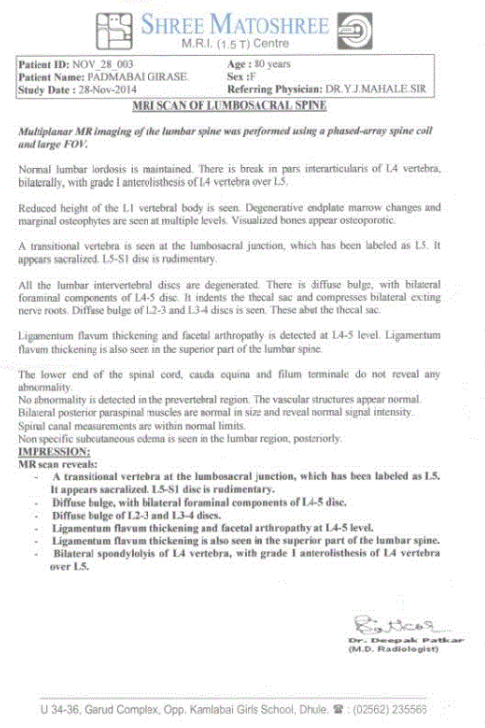

Figure 4: Report of MRI of lumbar spine.

\section{Discussion}

Regional anaesthesia is well known for complications. Major neurological sequelae after central blockade although rare but can be devastating for the patient and the anaesthetist. Post spinal anaesthetic sequelae manifesting as peripheral nerve symptoms such as motor weakness, hypoaesthesia, paresthesia and nerve root involvement resulting in peripheral neuropathy have been linked to the anaesthetic [3]. Also, features such as numbness, tingling, heaviness or burning 
sensations have been noted in patients after spinal anaesthesia with any local anaesthetic [4].

Neurological complications directly related to spinal anaesthesia may be caused by trauma, ischemia, infection or neurotoxicity. Though controversial, but local anesthetic solutions administered in clinical concentrations do not cause nerve damage, prolonged exposure and/or high concentrations of local anaesthetic solutions at the spinal roots have been shown to result in permanent neurological deficit $[5,6]$ (Figure 5).

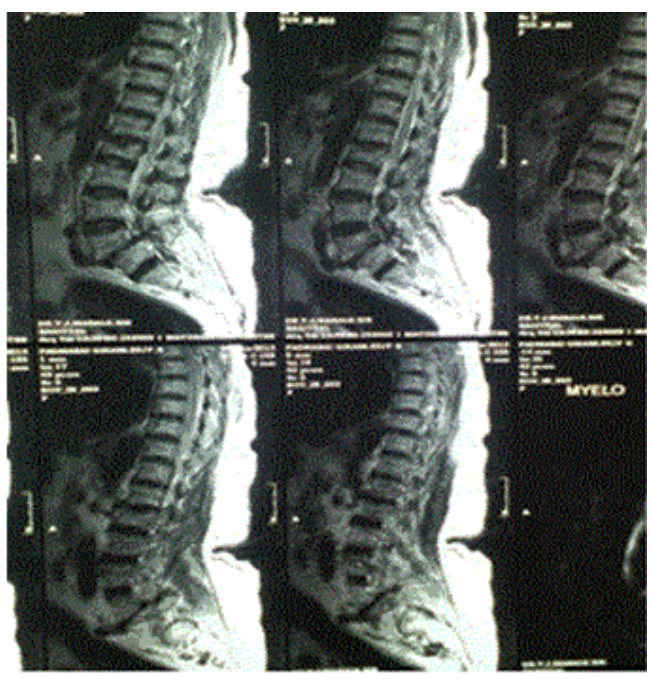

Figure 5: Film of MRI lumbar spine.

Prolonged hypotension following spinal anaesthesia has been reported in most cases to cause spinal cord ischemia or thrombosis of the anterior spinal artery [7]. Flaccid paraplegia due to anterior spinal artery thrombosis has been reported. Pre-existing neurologic lesion may also present with paraplegia following spinal anaesthesia [7]. Direct trauma to the spinal cord or nerve root may be due to multiple attempts, faulty technique and severe pain and electric shock like sensation felt by the patient at the time of insertion of the needle [8].

Thromboembolism is the most frequent serious complication following major orthopaedic surgery. Without prophylaxis, deep venous thrombosis (DVT) develops in approximately $50 \%$ of patients who undergo surgery.

The neurologic deficits following SA could be due to direct trauma by the needle or spinal cord ischemia due to either hypotension or vasoconstrictors used along with the local anesthetic agents $[9,10]$. Severe neurologic complications resulting from spinal anesthesia are rarely reported $[11,12]$. Our patient developed motor and sensory impairment in left lower limb after SA with corresponding changes in spinal MRI. The mechanisms responsible for the early onset of neurologic symptoms could be due to direct needle injury of the spinal cord and injection of the local anesthetic into the cord parenchyma, leading to immune-mediated changes and myelitis. Prognosis of these patients is gradual motor recovery over a period of days to months due to the resolution of edema. Unfortunately, the spinothalamic impairment may persist and in few cases leads to severe spontaneous pain over the affected segment.

\section{Conclusion}

Thorough pre-operative history and examination with proper knowledge of anatomy of spinal and epidural space is of utmost importance before undertaking management of any case for anaesthesia. Use of appropriate anaesthetic agent in proper dose and concentration should also be considered.

We suggest that during administration of spinal anaesthesia meticulous attention should be given to avoid direct needle trauma and intra-neural injection of local anaesthetics which is the most common cause of neurological sequelae.

\section{Clinical Message}

Neurological complications following lower limb surgeries under spinal anaesthesia are rare. In the case of paraesthesia during insertion of the needle, probability of needle trauma should be considered. In the case if any neurological complication is suspected prompt neurological intervention should be encouraged as patient is our utmost priority.

\section{References}

1. Agarwal A, Kishore K (2009) Complications and controversies of regional anaesthesia: A review. Indian J Anaesth 53: 543-553.

2. Kane RE (1981) Neurologic deficits following epidural or spinal anesthesia. Anesth Analg 60: 150-161.

3. Phillips OC, Ebner H, Nelson AT, Black MH (1969) Neurologic complications following spinal anesthesia with Lidocaine:a prospective review of 10,440 cases. Anesthesiology 30: 284-289.

4. Dripps RD, Vandam LD (1954) Long term follow-up of patients who received 10,098 spinal anesthetics: failure to discover major neurological sequelae. J Am Med Assoc 156: 1486-1491.

5. Ross BK, Coda B, Heath CH (1992) Local anaesthetic distribution in a spinal model: a possible mechanism of Neurological injury after continuous spinal anaesthesia. Reg Anesth 17: 69-77.

6. Tarkkila P, Huhtala J, Tuominen M (1995) Transient radicular irritation after spinal anaesthesia with hyperbaric 5\% lignocaine. Br J Anaesth 74: 328-915.

7. Rege AS, Navarange S, Ravigopal N, Rohondia O (2002) Complete flaccid paralysis following spinal anaesthesia - A case report. Indian J Anaesth 46: 58-60.

8. Kim SH, Song GS, Son DW, Lee SW (2010) Neurologic complication following spinal epidural anesthesia in a patient with spinal intradural extramedullary tumor. J Korean Neurosurg Soc 48: 544-546.

9. Loo CC, Irestedt L (1999) Cauda equine syndrome after spinal anaesthesia with hyperbaric 5\% lignocaine: A review of six cases of cauda equina syndrome reported to the Swedish Pharmaceutical insurance 1993-1997. Acta Anaesthesiol Scand 43: 371-379.

10. Auroy Y, Narchi P, Messiah A, Litt L, Rouvier B, Samii K (1997) Serious complications related to regional anaesthesia: Results of a prospective survey in France. Anesthesiol 87: 479-486.

11. Dahlgren N, Tornebrandt K (1995) Neurological complications after anesthesia: A follow-up of 18000 spinal and epidural anaesthetics performed over 3 years. Acta Anaesthesiol Scand 39: 872-880.

12. Vekariya RD, Chadha IA, Shah TD, Shukla MI, Jani CR (2004) Persistent lower limb weakness following spinal anaesthesia: Two case reports. J Anaesth Clin Pharmacol 20: 179-182. 